\title{
Maintenance of Certification ${ }^{\circledR}$, Maintenance of Public Trust
}

\author{
Kevin C. Chung, MD, MS ${ }^{1}$, Philip J. Clapham, BS ${ }^{2}$, and Donald H. Lalonde, MD $^{3}$ \\ ${ }^{1}$ Professor of Surgery, Section of Plastic Surgery, Department of Surgery, The University of \\ Michigan Health System; Ann Arbor, MI \\ ${ }^{2}$ Research Assistant, Section of Plastic Surgery, Department of Surgery, The University of \\ Michigan Health System; Ann Arbor, MI \\ ${ }^{3}$ Professor of Surgery, Plastic Surgery, Dalhousie University, Saint John, Canada
}

\section{Abstract}

The Maintenance of Certification ${ }^{\circledR}(\mathrm{MOC})$ program has been well received by many physicians, but faced significant opposition from others, who complain that it is overly tedious, costly, and irrelevant to their practice. This article offers a consolidated and concise history of the MOC program and a summary of what plastic surgeons need to know to successfully complete the American Board of Plastic Surgery's (ABPS) own MOC requirements. The authors have justified each step of the ABPS's MOC process in terms of how it improves the quality of care delivered to Plastic Surgery patients. Finally, a summary of research is presented that demonstrates both that the public supports the MOC process for all physicians and that continuing education and formal assessment and improvement initiatives have been linked in multiple studies to a better and more evidence-based medical practice.

\section{Keywords}

MOC; ABPS; ABMS

\begin{abstract}
The Maintenance of Certification ${ }^{\circledR}$ (MOC) program has been controversial since its presentation as the official certification policy of the American Board of Medical Specialties (ABMS) in the year 2000. Some physicians have criticized the fundamental ideology of the program, accusing it of stratifying the physician workforce into a "caste system,"1 whereas other opponents complain about its overly tedious policies and requirements. 2 Although each specialty board's MOC program is required to meet basic criteria, each ABMS member board is responsible for devising its own methodology for executing the MOC core principles. Consequently, each board's MOC program is slightly different. Despite the differences between programs, physicians across specialties share the sentiment that many components of their boards' programs are "extremely complex and problematic...esoteric, not relevant to practice, and full of minutiae." 3,4 Others have questioned the true worth of the program 2,5 and have accused the process of being "excessively commercialized,"
\end{abstract}

Corresponding author and reprint requests sent to: Kevin C. Chung, MD, MS, Section of Plastic Surgery, The University of Michigan Health System, 1500 E. Medical Center Drive, 2130 Taubman Center, SPC 5340, Ann Arbor, MI 48109-5340, Phone: 734-936-5885, Fax: 734-763-5354, kecchung @med.umich.edu.

Publisher's Disclaimer: This is a PDF file of an unedited manuscript that has been accepted for publication. As a service to our customers we are providing this early version of the manuscript. The manuscript will undergo copyediting, typesetting, and review of the resulting proof before it is published in its final citable form. Please note that during the production process errors may be discovered which could affect the content, and all legal disclaimers that apply to the journal pertain.

Financial Disclosure: None of the authors has a financial interest in any of the products or services mentioned in this manuscript. 
costly, and much more time-consuming than their board leaders realize. ${ }^{6,7}$ As a result, specialty boards have been accused of "alienating good, responsible physicians." 3

Despite this faction of resistance, an increasing body of literature supports the MOC process and has become explicitly made evident that MOC is "here to stay." 8 To clarify the MOC process and hopefully alleviate some of the confusion and misgivings of many physicians who unsuspectingly had MOC thrust upon them without their consents, the aim of this paper is to explore the history, rationale, and philosophy of the MOC program. We plan to elucidate the reasons for creating the MOC program, how the MOC process works, and the role of the MOC program in improving the quality of physician care. Specifically, we will address how the American Board of Plastic Surgery has designed their MOC program and what plastic surgeons will need to do to successfully maintain their certification. To see how the philosophy of specialty board certification evolved over time into today's MOC program, it is helpful to trace a brief history of how the ABMS was formed and their role in certifying physicians in different specialties. In 1917, the American Board of Ophthalmology was incorporated as an offshoot of the American Academy of Ophthalmology, and it was the first specialty-oriented institution to certify physicians as having adequate training and expertise within a specialty field. During the next fifteen years, the American Boards of Otolaryngology, Obstetrics and Gynecology, and Dermatology were formed (in that order). These four special boards, along with the American Medical Association's (AMA) Council on Medical Education, the American Hospital Association, the Federation of State Medical Boards, and the Association of American Medical Colleges (AAMC), created the Advisory Board of Medical Specialties in 1933. The purpose of the Advisory Board was to furnish an opportunity for the discussion of problems common to the different boards, act in an advisory capacity, and stimulate improvement in postgraduate medical education. ${ }^{9}$

Over the next four decades, national specialty organizations representing most specialty fields were incorporated and subsequently joined the Advisory Board. The American Board of Plastic Surgery (ABPS) began in 1937 as a subsidiary of the American Board of Surgery and gained independent board status in 1941. Following a reorganization in 1970, the Advisory Board was renamed the American Board of Medical Specialties (ABMS). Today the ABMS is responsible for setting the standards for the boards' certification processes and making sure that these processes are carefully and objectively executed. The ABMS has 24 specialty member boards, which as a group offer 37 general specialty certificates and 94 subspecialty certificates. The ABMS can claim members in $89 \%$ of all licensed US physicians. ${ }^{9}$

The initial certification examination for a given specialty is created by each specialty board. Its purpose is to assess the relevant medical expertise and clinical decision-making skills of physicians who have completed graduate medical education programs within that specialty. One role of the ABMS is to continuously scrutinize these examinations and ensure that there is documentation that they are statistically reliable, reproducible, and valid. Because physicians traditionally undergo the initial examination process following their specialty training, the ABMS has joined forces with the Accreditation Council for Graduate Medical Education (ACGME) to develop a curriculum of six "core competencies" that they believe are important for proficiency in any specialty. These six competencies are: medical knowledge, patient care, interpersonal and communicative skills, professionalism, practicebased learning and improvement, and systems-based practice. These competencies have been set by the ACGME as the core principles of their programs' curriculum, and the ABMS have incorporated measurements of these competencies into their certification process requirements. Due to the rigor and extensiveness of the process, certification from 
one of the ABMS specialty boards is widely accepted as an indicator of a specialist's superior medical knowledge and their high quality of care. ${ }^{10,} 11$

In the 1960's and 1970's, the quality movement began to take root and evidence-based healthcare practices slowly started to be adopted as the healthcare model in the US. One component of this movement was that significantly more accountability began to be demanded from physicians and hospitals to justify their practices and decisions. Concerns about the gradual degradation of physicians' clinical skills and medical knowledge over time led the ABMS to institute periodic re-certification as its official policy in 1973. Throughout the next two decades, most boards switched from granting life-time certificates to offering time-limited certificates that physicians would need to renew every 6 to 10 years by successfully repeating the examination process. ${ }^{12,13}$

Over the next several decades, the quality movement gained momentum because of concerns about the significant variations in healthcare practices. ${ }^{14,15}$ Public health research in the 1980's and 1990's revealed large quality-of-care gaps when comparing outcomes across our nation's healthcare systems. Most of this research documented the underuse or misuse of important evidence-based processes of care. ${ }^{16}$ Other startling research was presented in To Err is Human: Building a Safer Health Care System, a 2000 report by the Institute of Medicine (IOM) to showcase that preventable errors in U.S. hospitals were responsible for as many as 98,000 deaths per year.17 A follow-up IOM report speculated that the faulty clinical decisions, processes of care, and delivery systems that caused these errors resulted from specific failures on the part of both hospital administration and physicians to translate knowledge into practice.18 The IOM labeled this "the quality chasm," and blamed its existence on doctors who do not practice evidence-based medicine, but instead rely on their own individual perceptions of what are the appropriate treatments. Additionally, health services research showed that physician knowledge on a given subject does not necessarily translate proper clinical decision-making into proper patient care.19 In response to the Quality Movement, numerous physician oversight groups and programs were formed. Additionally, the Joint Commission on Accreditation of Health Care Organizations (JCAHO) and the Centers for Medicare and Medicaid Services (CMS) became increasingly more vigilant in overseeing physicians' clinical decisions and their patients' outcomes by instituting mandatory quality improvement initiatives, including the Pay-for-Performance reimbursement system.20, 21

The end result of the healthcare quality issues was that the public began demanding that physicians and the medical community be more accountable for their care by committing to quality improvement efforts that identify sub-par practices and working to improve areas of deficiency to acceptable evidence-based standards. The ABMS response has been the creation of the Maintenance of Certification ${ }^{\circledR}$ (MOC) program. Recognizing that a knowledge-based examination, even a fully comprehensive one, is insufficient to ensure that certified specialists are regularly adhering to high performance standards, the MOC process is a more inclusive assessment of physicians' knowledge and clinical skills. ${ }^{10}$

In 1998, the ABMS created the Task Force on Competence, which was responsible for creating a program of continuous quality assessment and improvement for physicians that would be based on the six competencies set up with the ACGME as the core principles for graduate medical education curriculum. The result was the proposal of the multidimensional Maintenance of Certification ${ }^{\circledR}$ program, which would be broken down into the following four components: professional standing, lifelong learning and self-assessment, cognitive expertise, and practice performance assessment. The basic ABMS guidelines for each component are listed in Table $1 .{ }^{10}$ (Table 1 ) However, the specialty boards were responsible for developing their own methods for fulfilling these requirements. In 2000, the 
24 member boards voted to change their certification from periodic re-certification by examination to the ongoing assessment process of the MOC program. Because the ABPS did not initiate time-limited certificates until 1995, its first recertification exam was not scheduled for administration until 2003. This gave the ABPS the unique opportunity to design its recertification process with the impending MOC changes in mind. For this reason, the ABPS was a forerunner amongst the ABMS specialty boards in implementing the new MOC strategy.

By 2006, the ABMS Board of Directors had approved the MOC program proposals of all 24 member Boards. Though keeping the traditional knowledge examination as a requirement, the other facets of the MOC include on-going continuing education and participation in selfassessment and improvement efforts in the years between examinations. Twenty-two of the 24 member boards set their programs so one full MOC cycle lasts 10 years, whereas the American Boards of Obstetrics and Gynecology and Family Medicine have set up more rigorous cycles that last 5 and 7 years, respectively. ${ }^{10}$ Many boards broke the cycle into blocks and require that a portion of the requirements be satisfied during each block, so in effect physicians are continuously participating in the MOC process rather than cramming in all the requirements in the final year. ${ }^{10}$

Even though the specialty boards enjoy autonomy in designing their MOC programs, an ABMS subcommittee, the Committee on Monitoring and Oversight of MOC (COMMOC), was created to serve in an active oversight role and ensure that member boards are fulfilling the essential ABMS requirements. To verify that all MOC guidelines are being followed and enforced, the member boards submit regular reports to the COMMOC on the state of their MOC program and physician participation. The directors review each board's program for continued compliance with the general guidelines. ${ }^{9}$

To fulfill the minimum requirements of Part 1 "Professional Standing" of the MOC program, the ABMS requires only that the physician prove that (1) he/she holds a current unrestricted state medical license (or province for Canadian physicians) and (2) that their license never has been suspended for any period of time in the years since their last certification date. ${ }^{22}$ Some boards, however, go above and beyond simple state licensure and require licenses and/or membership from different agencies. The American Board of Plastic Surgery (ABPS), for example, requires surgeons to submit: (1) documentation of their membership in one of its twenty sponsor organizations, (2) three completed peer-review forms from the ABPS website where colleagues use a Likert scale to rank the plastic surgeon on the 12 characteristics listed in Table 2, and (3) documentation of facility accreditation for outpatient surgical centers where the surgeon works. Additionally, beginning in 2011, surgeons will have to submit documented verification of privileges or appointments to practice in a hospital accredited by the Joint Commission. ${ }^{23}$ (Table 2)

Although the ABMS requirements for Part 1 of the MOC program are straightforward, the other components are more open for interpretation on how the requirements are satisfied. The ABMS requires that Part 2, "Lifelong Learning and Assessment," consist of a minimum of 500 hours of Continuing Medical Education (CME) credits over a 10 year period, 250 of which must be Category $1 \mathrm{CME}$ credits. Additionally, the ABMS requires 350 of the 500 credits to be specialty-specific, and the remaining credits can be from other topics (for example, general clinical topics, ethics, and statistics). ${ }^{22}$ The ABPS requires in years 3, 6, and 9 of the certification cycle that surgeons submit an official CME summary report verifying that they have earned 150 CME credits in the last 3 years. Sixty of these hours must be Category 1 credits, 50 must be for plastic surgery activities, and 20 must be patientsafety related credits. The American Society of Plastic Surgeons (ASPS) offer an electronic tracking system for CME credits, where physicians upload certificates from completed CME 
activities and the system records and categorizes the credits. Official forms from this service are available for physicians to submit to the ABPS as part of the MOC.23

Part III of the MOC, "Cognitive Expertise," consists of the traditional knowledge examination. All specialty boards administer the exams in a computerized format at computer-based testing centers (for example, Prometric $\odot$ test centers) across the United States and Canada. This ensures format and question uniformity and allows easy security regulations. In applying to take the exam, physicians must provide documentation that they have treated a certain number of conditions within that specialty in the previous 12 months. Instead of taking two examinations, physicians who sub-specialize within a specialty are able to take a hybrid test that combines general specialty questions and specific subspecialty questions. In this way they are able to maintain multiple board certifications without having to repeat each step of the process for each certificate. ${ }^{22}$

The ABPS allows plastic surgeons to take the exam during years 8 through 10 of the MOC cycle. The examinations are offered at testing centers typically from April 1 to April 30 each year, but each surgeon is allowed to take the exam only once per year. In their application, surgeons must provide a 6-month case log that documents an adequate number of plastic surgery cases. Table 3 lists the number of required cases for the Comprehensive Plastic Surgery Certification and the various subspecialty certifications also offered by the ABPS. ${ }^{23}$

Each exam consists of 200 questions. The subspecialty exams include 50 "General Plastic Surgery" questions and 150 subspecialty specific questions. The questions are designed to test clinical and surgical expertise and emphasize current practices based on the highest level evidence in the literature. To provide continuity between the components of the MOC Program, the ABPS draws a number of the exam questions from the CME articles that were published in Plastic and Reconstructive Surgery, so physicians can prepare for the examination while engaging in continuing education. Also, a study guide in CD-ROM form is offered by the ASPS with the help of the ABPS to help physicians prepare for the exam. ${ }^{23}$ The questions in the study guide provide practical useful materials that help plastic surgeons keep up with evidence-based information.

Part IV of the MOC process, "Performance in Practice," is the most innovative component of the MOC program and has been referred to as "the heart and soul of MOC," 10 because it directly measures physicians' clinical skills and even patient outcomes. The ABMS requires boards to assess data provided by each physician on the diagnoses, treatments, and outcomes from a sample of the surgeon's patients. This might include case logs, chart reviews, clinical databases, or patient survey tools. Subsequently, the board reviews the data and builds a portfolio that documents how the physician's diagnoses, treatment decisions, and patient outcomes compare to peers in their specialty and national benchmarks. Physicians then develop and submit an assessment of their deficiencies and describe their plan for improvement, as well as a timeline for how specific changes will be implemented. A specified period of time later, the specialty board revisits the physician's case and assesses if the physician's self-improvement plan is working. ${ }^{10}$

Component IV of the ABPS' MOC requires that in years 3, 6, and 9 of the MOC cycle (corresponding to the years CME credit documentation is due), plastic surgeons submit comprehensive reports on 10 consecutive patients who they have performed a particular surgical procedure during the past 3 years. The particular surgical procedure they choose to submit patient data, referred to as a tracer procedure, depends on which certification they are seeking. After choosing a tracer procedure, surgeons respond to a web-based module by answering questions about the block of 10 consecutive cases they have selected. (Table 4) 
They also complete a PRS CME quiz related to their tracer procedure or enroll in a related educational course sponsored by an ABPS sponsor organization. ${ }^{23}$

Once the web-module is completed and submitted, the surgeon receives a benchmarking report that compares his/her data to surgeons who have chosen the same tracer procedure. This database of MOC data will increase in validity every subsequent year as more physicians complete Component IV, thereby increasing the accuracy of the assessments of how a surgeon's practice compares to his/her peers. After reviewing the benchmarking report, the surgeon completes a self-improvement action plan module online, documenting the specific issues being targeted for improvement and the timeline for how improvement will be achieved. ${ }^{23}$

A summary of the ABPS' MOC requirements during the different years of the cycle is provided in Table 5. Obviously, this program requires an enormous investment in effort by the diplomates when compared to the previous re-certification program, especially the addition of the "Practice Performance Assessment," a program that is unlike any other in which they have previously participated. No one can deny the marked increase in time, money, and energy that physicians now invest in maintaining specialty certification. However, as the famous quote by our $26^{\text {th }}$ president Theodore Roosevelt goes, "Far and away, the best prize that life has to offer is the chance to work hard at work worth doing." And for every physician, improving the quality of care for their patients is undoubtedly work worth doing.

Because 2010 is the 5th year of the MOC program and not even one complete cycle has been completed, the outcomes of requiring physicians to engage in self-assessment and improvement initiatives are yet to be determined. However, many studies have demonstrated a positive and statistically significant association between specialty board certification and greater compliance with recommended treatments and superior patient outcomes. ${ }^{24-26}$ For example, several studies have associated certification with lower mortality and complication rates for a number of surgical procedures, including carotid endarterectomy,27 colon resection,28 aortic aneurysm resection,27 and peptic ulcer surgery. ${ }^{29}$ Another study showed that patients who saw board certified physicians were more likely to receive recommended preventative care (for example, vaccines) and health screenings. ${ }^{30}$ Additionally, support from both the medical community 12,19 and the public 31 has been strong for continuing physician education and self-assessment/improvement initiatives. The ABMS' official "overarching goal" for the MOC is to "protect the public and patients by attesting to the quality, safety, and effectiveness of US medical practitioners." 2 Through their participation in the MOC program, physicians demonstrate their commitment to continuous improvement in their medical knowledge and care delivery. To our patients, participation is a statement that providing quality patient care is our primary priority.

\section{Acknowledgments}

Supported in part by a Midcareer Investigator Award in Patient-Oriented Research (K24 AR053120) from the National Institute of Arthritis and Musculoskeletal and Skin Diseases (to Dr. Kevin C. Chung).

\section{References}

1. Bennett BD. Maintenance of Certification requirements for pathologists-reply. Human Pathology. 2006; 38(3):525.

2. Lipner R, Bylsma W, Arnold G, Fortna G, Tooker J, Cassel C. Who is Maintaining Certification in Internal Medicine- and Why? A National Survey 10 Years after Initial Certification. Ann Intern Med. 2006; 144:29-36. [PubMed: 16389252] 
3. White B. Are you ready for Maintenance of Certification? Family Practice Management. 2005; 12(1):42-48. [PubMed: 15709522]

4. Levinson W, King TE. American Board of Internal Medicine Maintenance of Certification Program. New England Journal of Medicine. 2010; 362(10):948-952. [PubMed: 20220192]

5. Steinbrook R. Renewing Board Certification. N Engl J Med. 2005 November 10.353:1994-1997. 2005. [PubMed: 16282173]

6. Volpintesta E. Maintenance of certification should not be used as requirement for relicensure. http:// blog.yjhm.org/2009/10/maintenance-of-certification-should-not.html.

7. Drazen J, Weinstein D. Considering Recertification. New England Journal of Medicine. 2010; 362(10):946-947. [PubMed: 20220191]

8. Kerr RR. MOC is here to stay; now it's time to educate yourself. Urology Times. 2007; 35(1):3.

9. Miller S. ABMS' Maintenance of Certification. Clinical orthopaedics and Related Research. 2006; 449:155-158. [PubMed: 16788404]

10. Horowitz S. Invited Article: Maintenance of Certification. Neurology. 2008; 71:605-609. [PubMed: 18711115]

11. Buyske J. For the Protection of the Public and the Good of the Specialty. Arch Surg. 2009; 144(2): 101-103. [PubMed: 19221318]

12. O'Day D. Maintenance of Certification and the Outside World. Arch Opthamol. 2004; 122:767769.

13. Becker G, Roberts A, Hattery R. Why Take the Vascular and Interventional Radiology Maintenance of Certification Examination or Maintain a Subspecialty Certificate in Vascular and Interventional Radiology? J Vasc Interv Radiol. 2004; 15:531-533. [PubMed: 15178711]

14. Chung KC, Ram AN. Evidence-based medicine: the fourth revolution in American medicine? Plast Reconstr Surg. 2009 Jan; 123(1):389-398. [PubMed: 19116577]

15. Chung KC, Rohrich RJ. Measuring quality of surgical care: is it attainable? Plast Reconstr Surg. 2009; 123(2):741-749. [PubMed: 19182638]

16. Corboy J, Elkin M. Maintenance of certifiaction: Ready or not, here it comes. Neurology. 2008; 71:544-545. [PubMed: 18711107]

17. Kohn, LT.; Corrigan, JM.; Donaldson, MS., editors. America IoMCoQoHCi. To Err is Human: Building a Safer Health System. Washington, D.C: National Academy Press; 2000.

18. Committee on Quality Health Care in Amerca IoM. Crossing the quality chasm: a new health system for the 21st century. Washington, DC: National Academy Press; 2001.

19. Cassel C, Holmboe E. Credentialing and Public Accountability: A Central Role for Board Certification. JAMA. 2006; 295(8):939-940. [PubMed: 16493109]

20. Chung KC, Shauver M. Measuring quality in healthcare and its implications for pay for performance initiatives. Hand Clinics. 2009; 25(1):71-81. [PubMed: 19232918]

21. Ezaki M, Marcus R. Maintenance of Certification for Orthopaedic Surgeons. J Bone Joint Surg (American). 2009; 91:222-226.

22. Darcy M. Maintenance of Certification: A Primer for Interventional Radiologists. J Vasc Interv Radiol. 2006; 17:S175-S181. [PubMed: 17142700]

23. American Board of Plastic Surgery I. Maintenance of Certification in Plastic Surgery: Booklet of Information. Philadelphia: 2010.

24. Sutherland K, Leatherman S. Analysis and Comment. BMJ. 2006; 333:439-441. [PubMed: 16931845]

25. Weiss K. Introductory Remakrs by the President of the American Board of Medical Specialties. Acad Emerg Med. 2008; 15(11):982-983. [PubMed: 18945229]

26. Holmboe E, Wang Y, Mechan T, et al. Association Between Maintenance of Certification Examination Scores and Quality of Care for Medicare Beneficiaries. Arch Intern Med. 2008; 168(13):1396-1403. [PubMed: 18625919]

27. Pearce W, Parker M, Feinglass J, Ujiki M, Manheim L. The importance of surgeon volume and training in outcomes for vascular surgical procedures. J Vasc Surg. 1999; 299:768-776. [PubMed: 10231626] 
28. Prystowsky J, Bordage G, Feinglass J. Patient outcomes for segmental colon resection according to surgeon's training, certification, and experience. Surgery. 2002; 132:663-670. [PubMed: 12407351]

29. Kelly J, Hellinger F. Physician and hospital factors associated with mortality of surgical patients. Med Care. 1986; 24:785-800. [PubMed: 3762245]

30. Pharm H, Schrag D, Hargraves J, Bach P. Delivery of preventive services to older adults by primary care physicians. JAMA. 2005; 294:473-481. [PubMed: 16046654]

31. Noone R. Everyone Wins. Plastic and Reconstructive Surgery. 2005:2137-2139. [PubMed: 15923870] 
Table 1

Official ABMS Guidelines for the 4 MOC Competencies

\begin{tabular}{|l|l|}
\hline Competency Description & Guideline \\
\hline Part I-Professional Standing & $\begin{array}{l}\text { Medical specialists must hold a valid, unrestricted medical license in at least one state or jurisdiction } \\
\text { in the United States or Canada. }\end{array}$ \\
\hline $\begin{array}{l}\text { Part II-Lifelong Learning and Self- } \\
\text { Assessment }\end{array}$ & $\begin{array}{l}\text { Physicians participate in educational and self-assessment programs that meet specialty-specific } \\
\text { standards that are set by their member board. }\end{array}$ \\
\hline Part III-Cognitive Expertise & $\begin{array}{l}\text { They demonstrate, through formalized examination, that they have the fundamental, practice-related } \\
\text { and practice environment-related knowledge to provide quality care in their specialty. }\end{array}$ \\
\hline $\begin{array}{l}\text { Part IV-Practice Performance } \\
\text { Assessment }\end{array}$ & $\begin{array}{l}\text { They are evaluated in their clinical practice according to specialty-specific standards for patient care. } \\
\text { They are asked to demonstrate that they can assess the quality of care they provide compared to peers } \\
\text { and national benchmarks and then apply the best evidence or consensus recommendations to improve } \\
\text { that care using follow-up assessments. }\end{array}$ \\
\hline
\end{tabular}

http://www.abms.org/Maintenance_of_Certification/MOC_competencies.aspx. Accessed 2/21/2010. 
Table 2

Physician Characteristics Evaluated on the ABPS MOC Peer Review Form

\begin{tabular}{|c|c|}
\hline Characteristic & Description \\
\hline Respect & $\begin{array}{l}\text { Shows personal commitment to honoring the choices and rights of other persons, especially regarding their } \\
\text { medical care. }\end{array}$ \\
\hline Medical Knowledge & Demonstrates well-integrated knowledge. \\
\hline Integrity & Shows commitment to honesty and trustworthiness in evaluating and demonstrating own skills and abilities. \\
\hline Consults/Communication & $\begin{array}{l}\text { Provides consultation in a timely fashion and communicates findings, treatment plan and each MD's role back } \\
\text { to the referring MD. }\end{array}$ \\
\hline Compassion & $\begin{array}{l}\text { Appreciates patients' and families' special needs for comfort and help, but avoids inappropriate emotional } \\
\text { involvement. }\end{array}$ \\
\hline Responsibility/Commitment & Commitment to clinical activities and accepts responsibility for own actions and decisions. \\
\hline Problem-Solving & Assesses information, risks and benefits; identifies major issues or make timely decisions. \\
\hline Patient Management Skills & Ability to diagnose and treat patients and coordinate care in this clinical setting. \\
\hline Technical Skills & $\begin{array}{l}\text { Good results, low complication rates and high satisfaction rates. Would refer future patients on the basis of } \\
\text { technical accomplishments. }\end{array}$ \\
\hline Teamwork/Collaboration & Able to work with staff and other health professionals and accepts and respects the contribution of others \\
\hline Record Keeping & Records are timely, complete and accurate, resulting in smooth transition of care between providers. \\
\hline Overall Clinical Skills & Demonstrates overall sound clinical skills. \\
\hline
\end{tabular}

* American Board of Plastic Surgery I. MOC-PS Peer Review Form. Philadelphia 2010. Available at: https://www.abplsurg.org/ModDefault.aspx?section=DipMOCPS. Accessed 2/21/2010. 
Table 3

Eligibility Requirements for the ABPS Cognitive Exam

\begin{tabular}{|l|c|}
\hline Certification & Number of Cases in Past 6 Months \\
\hline Comprehensive Plastic Surgery & 25 \\
Cosmetic Surgery & 38 \\
Hand Surgery & 25 \\
Craniomaxillofacial Surgery & 10 \\
\hline
\end{tabular}

* American Board of Plastic Surgery I. Maintenance of Certification in Plastic Surgery: Booklet of Information. Philadelphia 2010. Available at: https://www.abplsurg.org/ModDefault.aspx?section=BOI_MOCPS. Accessed 2/21/2010. 
Table 4

Tracer Procedures for ABPS MOC Part IV- "Performance in Practice"

\begin{tabular}{|c|c|c|c|}
\hline Comprehensive & Cosmetic & Craniomaxillofacial & Hand \\
\hline $\begin{array}{cl}\mathbf{1} & \text { Reduction } \\
& \text { Mammaplasty } \\
\mathbf{2} & \text { Breast } \\
& \text { Reconstruction } \\
\mathbf{3} & \text { Pressure Sores } \\
\mathbf{4} & \text { Facial Skin } \\
& \text { Malignancy } \\
\mathbf{5} & \text { Lower Extremity } \\
& \text { Acute Trauma }\end{array}$ & $\begin{array}{cl}\mathbf{1} & \begin{array}{l}\text { Augmentation } \\
\end{array} \\
\mathbf{2} & \text { Mammaplasty } \\
\mathbf{3} & \begin{array}{l}\text { Fuce Lift } \\
\text { Lipection Assisted }\end{array} \\
\mathbf{4} & \text { Blepharoplasty } \\
\mathbf{5} & \text { Abdominoplasty }\end{array}$ & $\begin{array}{ll}\mathbf{1} & \text { Cleft Palate } \\
\mathbf{2} & \text { Zygomatic Fractures } \\
\mathbf{3} & \text { Genioplasty } \\
\mathbf{4} & \begin{array}{l}\text { Secondary Cleft Nasal } \\
\text { Deformity }\end{array} \\
\mathbf{5} & \begin{array}{l}\text { Non-syndromic } \\
\text { craniosynostosis }\end{array}\end{array}$ & $\begin{array}{lll}\mathbf{1} & \begin{array}{l}\text { Carpal Tunnel } \\
\text { Syndrome }\end{array} \\
\mathbf{2} & \begin{array}{l}\text { Dupuytren's } \\
\text { Disease }\end{array} \\
\mathbf{3} & \begin{array}{l}\text { Thumb carpo- } \\
\text { metacarpal } \\
\text { Arthritis }\end{array} \\
\mathbf{4} & \begin{array}{l}\text { Flexor Tendon } \\
\text { Laceration }\end{array} \\
\mathbf{5} & \begin{array}{l}\text { Metacarpal } \\
\text { Fracture }\end{array}\end{array}$ \\
\hline
\end{tabular}

* American Board of Plastic Surgery I. Maintenance of Certification in Plastic Surgery: Booklet of Information. Philadelphia 2010. Available at: https://www.abplsurg.org/ModDefault.aspx?section=BOI_MOCPS. Accessed 2/21/2010. 
Table 5

Requirements for ABPS MOC by Year in MOC Cycle

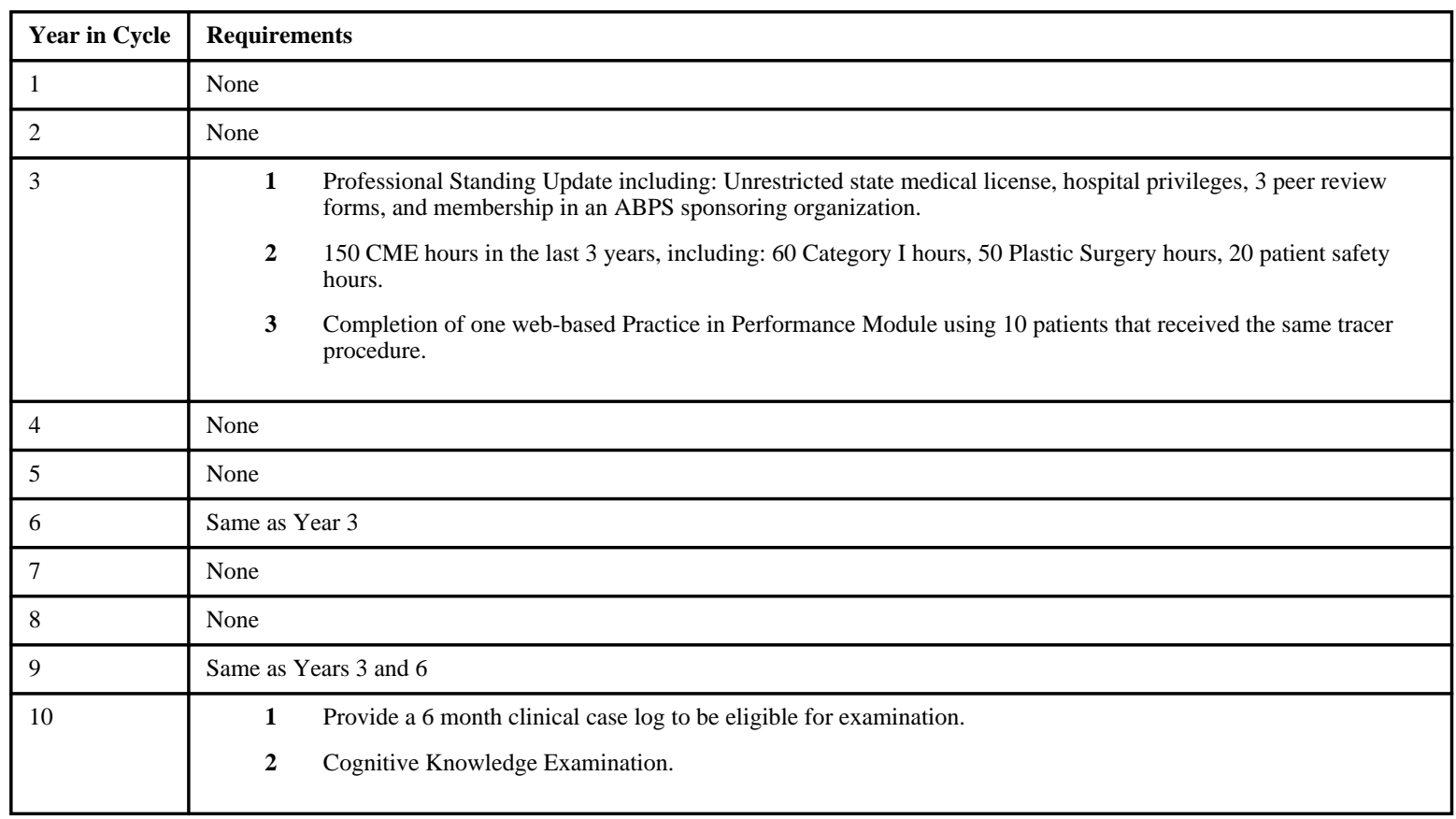

* American Board of Plastic Surgery I. Maintenance of Certification in Plastic Surgery: Booklet of Information. Philadelphia 2010. Available at: https://www.abplsurg.org/ModDefault.aspx?section=BOI_MOCPS. Accessed 2/21/2010. 